\title{
Use of an electron-beam evaporator for the creation of nanostructured pits in an insulating surface
}

\author{
Jeffrey M. Mativetsky, ${ }^{\text {a) }}$ Yoichi Miyahara, Shawn Fostner, \\ Sarah A. Burke, and Peter Grutter \\ Department of Physics, McGill University, Montreal, Quebec H3A 2T8, Canada
}

(Received 17 February 2006; accepted 22 April 2006; published online 9 June 2006)

\begin{abstract}
We demonstrate a method for creating monatomic-depth rectangular pits of controlled size in an alkali halide surface by using an electron-beam evaporator. Atomic resolution noncontact atomic force microscopy is used to characterize the structure and size distribution of the pits, with mean side lengths ranging from 6.5 to $20 \mathrm{~nm}$. It is also demonstrated that metal nanoparticles can be used to nucleate the growth of pits, resulting in pits with metal nanoparticles inside. (C) 2006 American Institute of Physics. [DOI: 10.1063/1.2210288]
\end{abstract}

While surface modifications induced by electronic transitions have been of fundamental interest for several decades, ${ }^{1,2}$ there is renewed interest in the field because of its relevance to nanofabrication. ${ }^{3}$ Moreover, the recent development of noncontact atomic force microscopy ${ }^{4}$ (NC-AFM) has opened up the possibility of measuring the topography of modified insulators with atomic resolution. ${ }^{5}$ This is of great importance since the influence of surface topography on the desorption process leading to surface modification remains largely unknown. ${ }^{1}$

Through excitation by electrons, ${ }^{1}$ photons, ${ }^{6}$ or ions, ${ }^{7}$ the desorption of atoms from ionic crystal surfaces is induced by the formation of Frenkel defects in the bulk ( $F$ and $H$ centers), which diffuse and recombine with the surface. ${ }^{1}$ At the first stages of the typically layer-by-layer surface removal, monatomic-depth rectangular pits are formed, which are several nanometers in size. Recently, these pits have been used to trap small numbers of SubPc molecules, ${ }^{3}$ an important step towards assembling a molecular electronic device on an insulating substrate. These well defined surface features may also serve to control the nucleation of metal nanostructures at surfaces. ${ }^{6}$ In this letter, we report on the use of an electronbeam evaporator as a source of charged particles for creating arrays of nanostructured pits and metal nanoparticles inside pits on a $\mathrm{KBr}(001)$ surface.

All of the sample preparation and characterization was performed in ultrahigh vacuum (base pressure $<4$ $\times 10^{-8} \mathrm{~Pa}$ ). The $\mathrm{KBr}$ surfaces were prepared by cleaving a crystal (Korth Kristalle, Germany) in situ along the (001) plane and then heating for $1 \mathrm{~h}$ at $150{ }^{\circ} \mathrm{C}$, in order to remove any residual surface charge. An Oxford Applied Research EGN4 electron-beam evaporator was used for the pit creation and metal deposition. During operation, charged particles are emitted as a result of the ionization of residual gas in the vacuum chamber, the ionization of target material, and the production of low energy electrons. To reduce the amount of charge impinging on the sample during evaporation, the evaporator is fitted with a grid held at $2 \mathrm{kV}$. With this setup, extremely small current densities are accessible $\left(<500 \mathrm{pA} / \mathrm{cm}^{2}\right)$, making it possible to finely tune the irradiation dose to the sample.

${ }^{a)}$ Electronic mail: jeffreym@physics.mcgill.ca
Tantalum (Alfa Aesar, 99.95\%) was used as the evaporator target material because its high melting point enables the use of a wide range of evaporator powers, and hence current densities. The pits were created by operating the evaporator at a low power, such that the sample is irradiated with a well defined dose of charge without depositing any tantalum. At higher powers, both charge and evaporated tantalum are emitted. During the irradiation, the $\mathrm{KBr}$ sample was held at $250{ }^{\circ} \mathrm{C}$. The current to the sample position was measured by replacing the $\mathrm{KBr}$ sample with an electrically conducting sample and using a Stanford Research Systems SR560 low-noise current preamplifier.

The NC-AFM measurements were performed at room temperature using a JEOL JSPM 4500A ultrahigh vacuum AFM. A Nanosurf phase-locked loop was used for the frequency detection and constant amplitude regulation. Cantilevers supplied by Nanosensors with a typical resonant frequency of $170 \mathrm{kHz}$ and a spring constant of $40-50 \mathrm{~N} / \mathrm{m}$ were employed.

In order to expose the samples to a well defined dose of charge, the current emitted by the evaporator was characterized. As shown in Fig. 1(a), as the power applied between the evaporator filament and the tantalum target is increased, the net current density at the sample position increases linearly as a result of the increased ionization of the background gas by the electron-beam of the evaporator. At about $80 \mathrm{~W}$, a deviation from linearity is observed due to the onset of evaporation and thus tantalum ions. Electrons also contribute to this measured current density. To determine the proportion of positive and negative charges and the total amount of charge incident on the sample, the current density was measured as a function of sample voltage [Fig. 1(b)]. At negative voltages, nearly all of the incoming electrons are deviated, resulting in a saturation of the current density. This saturated current density is the current due to positive ions. As the sample voltage is increased to positive values, greater numbers of stray scattered electrons are collected from the chamber, resulting in an increasingly negative current density. The electron current during pit creation is determined by calculating the difference between the net current at $0 \mathrm{~V}$ and the positive current. ${ }^{9}$ Based on these considerations, the beam of charge was made up of $70 \%$ positive ions and $30 \%$ electrons, with a slightly higher proportion of positive charge during 
(a)
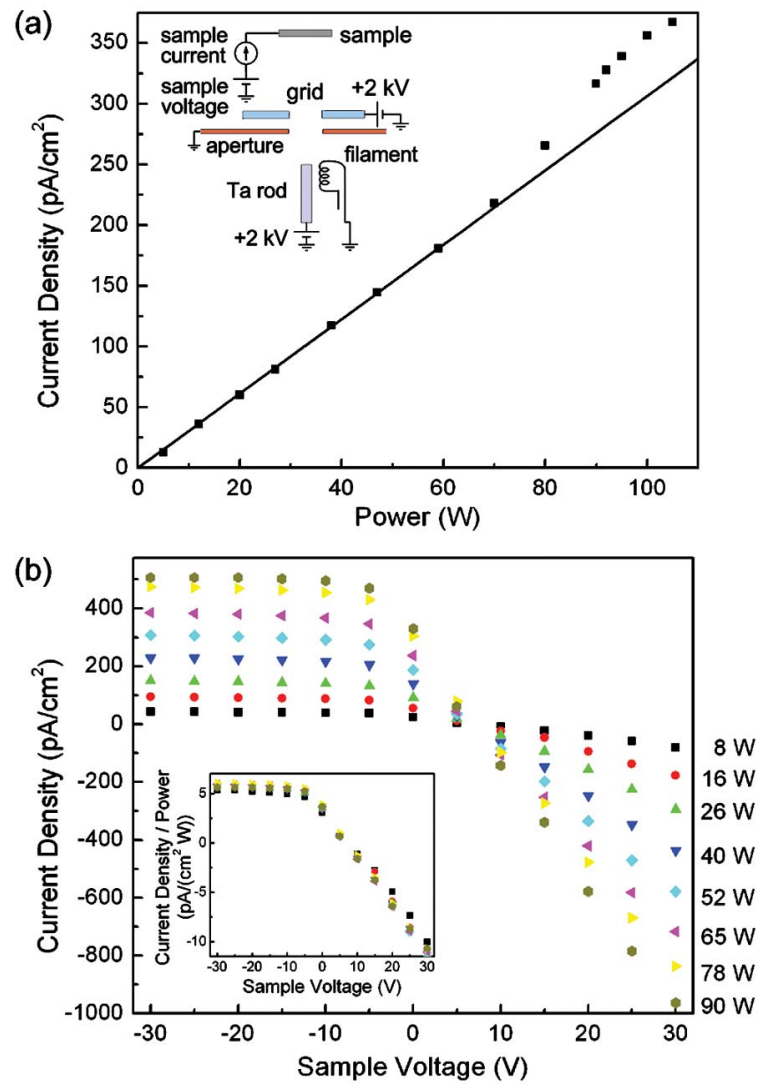

FIG. 1. (Color online) Current density at the sample position as a function of (a) applied evaporator power (the inset shows a schematic of the experimental setup) and (b) sample voltage. Because of the nearly linear relationship between current density and power, a universal relationship between current density and voltage is obtained by dividing the current density by the power (inset). This makes it possible to interpolate the current density for any applied power.

tantalum evaporation. The upper limit on the incoming particle energy is $2 \mathrm{keV}$.

In these experiments, powers of 26 and $52 \mathrm{~W}$ were used for pit creation, and a power of $92 \mathrm{~W}$ was employed for the production of tantalum nanostructures in pits, corresponding to total (positive+|negative|) current densities of 210, 430, and $680 \mathrm{pA} / \mathrm{cm}^{2}$. These current densities are about 1000 times smaller than those typically used in desorption experiments. ${ }^{1}$

As shown in Fig. 2(a), arrays of rectangular pits were produced in atomically flat terraces extending over areas larger than $1 \mu \mathrm{m}^{2}$. The pit edges are along the $\langle 001\rangle$ directions. In accordance with earlier observations of electron irradiated $\mathrm{KBr}$ surfaces, ${ }^{5}$ atomic resolution images [Fig. 2(b)] show that the structure and stoichiometry of the $\mathrm{KBr}(001)$ surface are preserved in the pit creation process.

Small and large rectangular pits were created in a $\mathrm{KBr}$ surface by using doses of 0.13 and $1.3 \mu \mathrm{C} / \mathrm{cm}^{2}$. Some measured sample characteristics are listed in Table I. As expected, a tenfold increase in dose leads to a nearly tenfold increase in the total amount of desorbed surface area. The presence of extended terraces made it possible to measure the size distribution of the pits. Histograms based on the analysis of more than ten images are shown in Fig. 2(c), with representative images shown as insets. The mean areas of the small and large pits are 42 and $390 \mathrm{~nm}^{2}$, corresponding to mean side lengths of 6.5 and $20 \mathrm{~nm}$, respectively. Although there is currently no theoretical framework for describing the
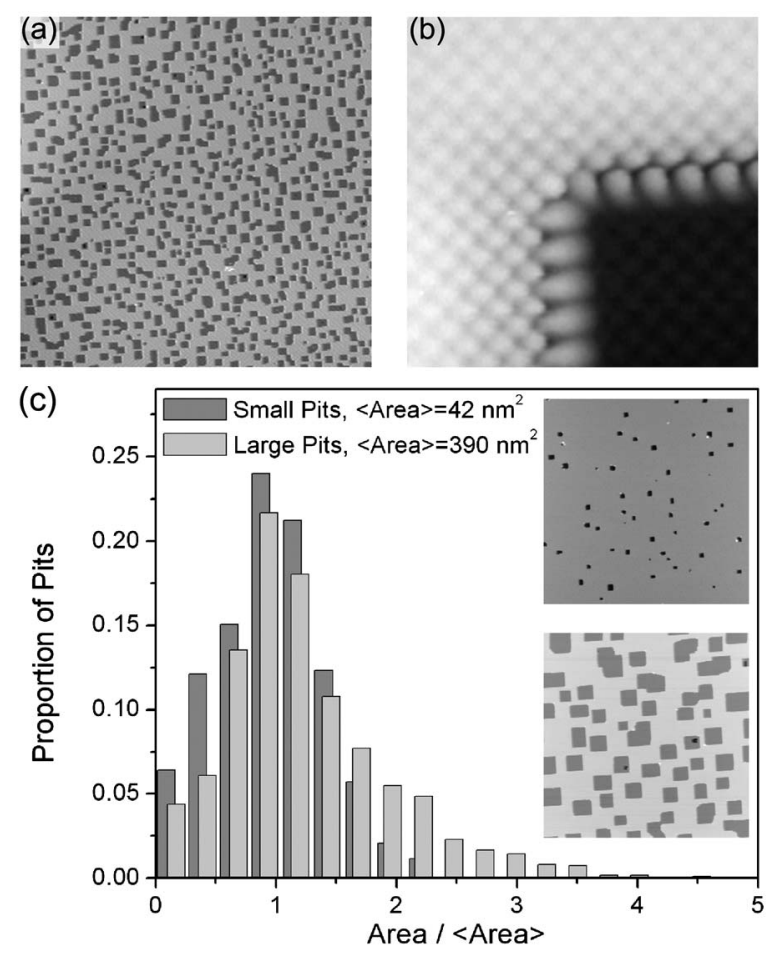

FIG. 2. NC-AFM topography measurements of rectangular pits in a $\mathrm{KBr}$ (001) surface (irradiation dose $=1.3 \mu \mathrm{C} / \mathrm{cm}^{2}$ ): (a) $1 \times 1 \mu \mathrm{m}^{2}$ overview of pits created in a large atomically flat terrace and (b) high resolution 6 $\times 6 \mathrm{~nm}^{2}$ image showing the atomic structure in a pit. (c) Size distributions of small and large pits created by using doses of 0.13 and $1.3 \mu \mathrm{C} / \mathrm{cm}^{2}$, with representative $300 \times 300 \mathrm{~nm}^{2}$ images shown as insets.

pit size distribution, the similarities between the distributions suggest a scaling behavior, analogous to that for island growth. ${ }^{10,11}$ The deviation between the distributions at high values is due to the coalescence of nearby large pits. Both samples have pit densities of about $500 / \mu \mathrm{m}^{2}$. In the language of growth studies, these samples are in the "pure growth" regime; i.e., the pit density is saturated. ${ }^{11}$ Pits created with a current density of $430 \mathrm{pA} / \mathrm{cm}^{2}$ showed the same characteristics as the $210 \mathrm{pA} / \mathrm{cm}^{2}$ samples, showing that the pit size and density do not depend on the current density.

Interestingly, a minimum pit size was observed to exist. It is hypothesized that these smallest pits are due to the impingement of single charged particles. To test this idea, the number of atoms missing in the smallest pits was compared with the average number of desorbed atoms per incident charged particle. The average area, based on the measurement of six minimum area pits, is $3.0 \mathrm{~nm}^{2}$, with a standard deviation of $0.6 \mathrm{~nm}^{2}$. This corresponds to the desorption of $28+5$ atoms. Based on the measurements of the total charge incident on the sample and the total surface area missing, on average, 31 atoms were ejected per charged particle for the large pits and 25 atoms per charged particle for the small pits. Both of these values correspond well with the number of atoms missing in the smallest pits. The reduced desorption rate for the sample with the smaller dose is consistent with the experiments of Such et al., which show a modulation in the desorption rate depending on the stage in the layer-bylayer desorption process. ${ }^{12}$ At the earliest stages of desorption, the desorption rate is somewhat suppressed, because of the relative scarcity of low-coordinated sites such as steps and kinks, where desorption is initiated. It should be noted that these smallest pits are sufficiently small to potentially license or copyright; see http://apl.aip.org/about/rights_and_permissions 
TABLE I. Measured sample characteristics for small pit, large pit, and pit with particle samples.

\begin{tabular}{lcccccc}
\hline \hline & $\begin{array}{c}\text { Current } \\
\text { density } \\
\left(\mathrm{pA} / \mathrm{cm}^{2}\right)\end{array}$ & $\begin{array}{c}\text { Dose } \\
\left(\mu \mathrm{C} / \mathrm{cm}^{2}\right)\end{array}$ & $\begin{array}{c}\text { Pit density } \\
\left(/ \mu \mathrm{m}^{2}\right)\end{array}$ & $\begin{array}{c}\text { Mean pit } \\
\text { area } \\
\left(\mathrm{nm}^{2}\right)\end{array}$ & $\begin{array}{c}\text { Percent } \\
\text { area } \\
\text { desorbed } \\
(\%)\end{array}$ & $\begin{array}{c}\text { Atoms } \\
\text { desorbed } \\
\text { per charge } \\
(/|e|)\end{array}$ \\
\hline $\begin{array}{l}\text { Small pits } \\
\begin{array}{l}\text { Large pits } \\
\text { Pits with } \\
\text { particles }\end{array}\end{array}$ & 210 & 0.13 & 515 & 42 & 2 & 25 \\
\hline \hline
\end{tabular}

immobilize and isolate individual large molecules, which otherwise have long diffusion lengths on insulating surfaces. $^{13,14}$

Finally, by using the evaporator at a power high enough to evaporate the tantalum target, pits were produced with tantalum nanoparticles inside (Fig. 3). The pits surrounding the tantalum are markedly smaller than the large pits shown in Fig. 2, despite the use of the same dose of charge. The mean area of the pits containing the tantalum nanoparticles is $47 \mathrm{~nm}^{2}$, corresponding to a mean side length of $6.9 \mathrm{~nm}$. While the pit size distribution is relatively sharply defined, there is a large tail at higher areas due to clustering and coalescence. The density of pits is nearly double that of samples without the metal structures (see Table I), indicating that the metal particles act as nucleation sites for the growth of the pits. Since the converse situation, the nucleation of metal particles at defect sites, is also known to occur, ${ }^{15}$ it is likely that both processes take place simultaneously. At atomic steps, some of the tantalum particles are not in pits;

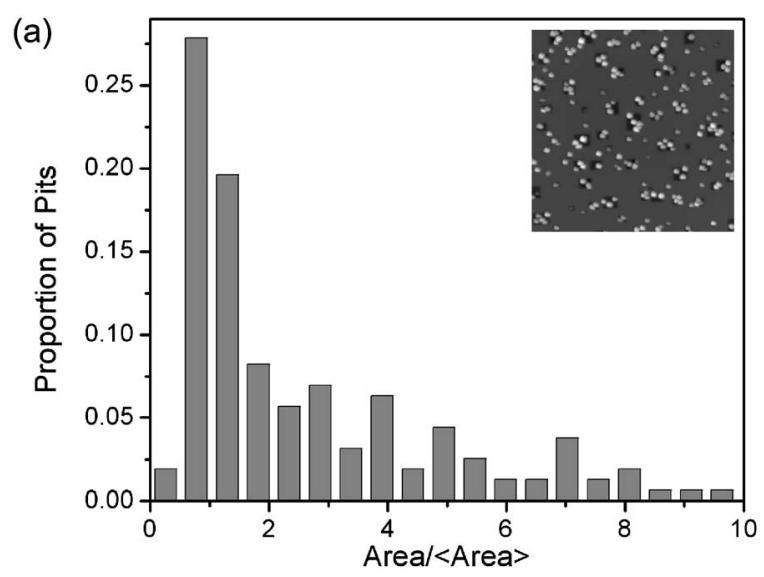

(b)

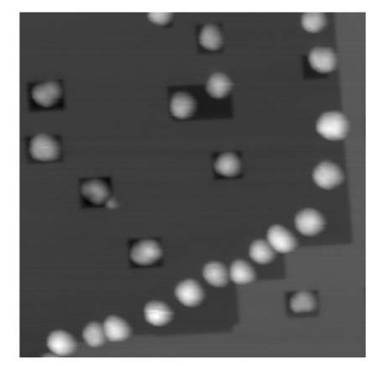

FIG. 3. Tantalum nanostructures inside monatomic-depth pits: (a) Pit size distribution with inset showing a representative $300 \times 300 \mathrm{~nm}^{2}$ area and (b) $100 \times 100 \mathrm{~nm}^{2}$ image showing Ta nanoparticles in pits and a receding $\mathrm{KBr}$ step. instead, the steps recede from the particles. This provides some information about the kinetics: first the tantalum nucleates at the $\mathrm{KBr}$ steps, and then the surface desorption takes place. This is visible in Fig. 3(b) where the tantalum nanoparticles initially decorated a rounded $\mathrm{KBr}$ step, which later became modified, favoring $\langle 001\rangle$ directions.

The desorption efficiency of 16 atoms per $|e|$ is nearly half of that for the pits without tantalum structures inside. Generally, after the initial desorption of a surface atom, predominantly at kink sites, ${ }^{5,8}$ an unzipping process is initiated along a step. In the case of this study, the unzipping may be interrupted by the presence of metal nanoparticles which physically obstruct the process.

In summary, we have demonstrated an alternative technique for creating monolayer-deep rectangular pits in an insulating surface, with improved control over the pit size. This approach also enables the creation of pits with metal nanoparticles inside. The metal particles serve as nucleation centers for the pits, while at the same time limiting pit expansion.

The authors thank R. Bennewitz for helpful discussions and the following agencies for funding: NSERC, CFI, NanoQuebec, FQRNT, and CIAR.

${ }^{1}$ M. Szymonski, J. Kolodziej, B. Such, P. Piatkowski, P. Struski, P. Czuba, and F. Krok, Prog. Surf. Sci. 67, 123 (2001).

${ }^{2}$ Desorption Induced by Electronic Transitions I, edited by N. H. Tolk, M. M. Traum, J. C. Tully, and T. E. Madey (Springer, Berlin, 1983).

${ }^{3}$ L. Nony, E. Gnecco, A. Baratoff, A. Alkauskas, R. Bennewitz, O. Pfeiffer, S. Maier, A. Wetzel, E. Meyer, and Ch. Gerber, Nano Lett. 4, 2185 (2004).

${ }^{4}$ Noncontact Atomic Force Microscopy, edited by S. Morita, R. Wiesendanger, and E. Meyer (Springer, Berlin, 2002).

${ }^{5}$ R. Bennewitz, S. Schär, V. Barwich, O. Pfeiffer, E. Meyer, F. Krok, B. Such, J. Kolodzej, and M. Szymonski, Surf. Sci. 474, L197 (2001).

${ }^{6}$ H. Höche, J. P. Toennies, and R. Vollmer, Phys. Rev. B 50, 679 (1994).

${ }^{7}$ F. Krok, J. Kolodziej, B. Such, P. Czuba, P. Piatkowski, P. Struski, and M. Szymonski, Nucl. Instrum. Methods Phys. Res. B 226, 601 (2004).

${ }^{8}$ V. Puchin, A. Shluger, Y. Nakai, and N. Itoh, Phys. Rev. B 49, 11364 (1994).

${ }^{9}$ The net current at $0 \mathrm{~V}$ is of relevance since $0 \mathrm{~V}$ is the condition used during pit creation.

${ }^{10}$ J. G. Amar and F. Family, Thin Solid Films 272, 208 (1996).

${ }^{11}$ H. Brune, Surf. Sci. Rep. 31, 121 (1998).

${ }^{12}$ B. Such, P. Czuba, P. Piatkowski, and M. Szymonski, Surf. Sci. 451, 203 (2000).

${ }^{13}$ S. A. Burke, J. M. Mativetsky, R. Hoffmann, and P. Grutter, Phys. Rev. Lett. 94, 096102 (2005).

${ }^{14}$ O. Pfeiffer, E. Gnecco, L. Zimmerli, S. Maier, E. Meyer, L. Nony, R. Bennewitz, F. Diederich, H. Fang, and D. Bonifazi, J. Phys.: Conf. Ser. 19, 166 (2005).

${ }^{15}$ B. F. Usher and J. L. Robins, Thin Solid Films 149, 351 (1987). 